\title{
A pedagogia social de Paulo Freire como contraponto da pedagogia globalizada
}

Scocuglia, Afonso Celso ${ }^{1}$

\section{Resumo}

Este trabalho pretende caracterizar as globalizações, algumas das suas influências sobre a educação e, especialmente, pensar os possíveis contrapontos aos determinismos da globalização hegemônica por meio dos principais conceitos da pedagogia social de Paulo Freire. Os numerosos eventos, as publicações e as constantes referências à obra e ao legado prático-teórico de Freire demonstram a possibilidade concreta da sua pedagogia vir a ser um contraponto vigoroso à influência da globalização hegemônica na educação mundial.

Paulo Freire. Educação. Cultura. Globalização.

\section{Resumen}

Este trabajo tiene como objetivo caracterizar las globalizaciones, algunas de sus influencias en la educación y, sobre todo, pensar en los posibles contrapuntos a los determinismos de la globalización hegemónica a través de los principales conceptos de la pedagogía social de Paulo Freire. Los numerosos eventos, publicaciones y las constantes referencias a la obra y el legado práctico-teórico de Freire demuestran la posibilidad real de que su pedagogía se convierta en un fuerte contrapunto a la influencia de la globalización hegemónica en la educación mundial.

Paulo Freire. Educación. Cultura. Globalización.

\footnotetext{
${ }^{1}$ Doutor em História, mestre em Educação, professor titular e pesquisador do Programa de Pós-Graduação em Educação da Universidade Federal da Paraíba (UFPB). e-mail:scocuglia@terra.com.br
} 


\section{Introdução}

Para iniciar um debate sobre globalização e educação penso que devemos partir da contestação de algumas falsas ideias que, de tão repetidas, tendem a se consolidar como ideologias. A primeira dessas ideias é a de que a globalização é um processo histórico recente e que não encontra paralelo na história. Para isso argumenta-se, inclusive, que seria produto das novas tecnologias da informação. Ora, o mundo começou a se tornar global, no sentido que o conhecemos, a partir dos séculos XV/XVI com as grandes navegações que invadiram as Américas.

Certamente, o processo de desenvolvimento do capitalismo mundial mostra-se como uma continuidade histórica, como consequência dos tempos e contra-tempos históricos do mundo liderado pelas forças dominadoras do Ocidente. A globalização, assim, não é recente, não é novidade histórica, parecendo muito mais uma nova tentativa de sobrevida do capitalismo, fundada na exacerbação da sua expansibilidade econômico-financeira facilitada pelas redes info-comerciais maximizadas. Vários autores colocam que tal processo é resultado da atual crise econômica que, motivada pela superprodução, acelera a centralização e a globalização do capital. Neste sentido, a globalização econômica e o neoliberalismo comercial seriam respostas à crise do capitalismo e produtores da concentração de riquezas e da exclusão social. A segunda falsa ideia é a de que a globalização é irrevogável, irreversível e inexorável, ou seja, é a única saída da pós-guerra fria cuja bipolaridade marcou o mundo no século $\mathrm{XX}$.

Assenta-se na premissa de que o capitalismo é a única via mundial, que o Leste (Rússia etc.) e a Ásia (China etc.) aderiram, que não há outras opções, que a história acabou e o neoliberalismo é a solução. A terceira e, talvez, a mais perniciosa das ideias, é de que, diante da avalanche globalizante alicerçada pelas duas ideias anteriores, não há nada a fazer senão aderirmos aos vencedores, líderes de um mundo único, no qual o individualismo, as guerras militares e civis (das grandes cidades e do campo), entre outras, são práticas e 
ideias que convergem e desaguam na globalização hegemônica, definitiva e fatal.

Com efeito, nos caminhos entrecruzados dessas ideias, também se desenvolvem argumentos de uma educação e de uma política educacional/ curricular cada vez mais padronizadas, globalizadas, supostamente marcadas e impostas por uma cultura educacional mundial comum, como defendem Meyer e seus colaboradores de Stanford (apud Dale, 2004). Segundo Dale, neste prisma,

a globalização é frequentemente considerada como representando um inelutável progresso no sentido da homogeneidade cultural, como um conjunto de forças que estão a tornar os Estados-nação obsoletos e que pode resultar em algo parecido como uma política mundial, e como refletindo 0 crescimento irresistível da tecnologia da informação. (Idem, p. 424).

\section{As globalizações contingentes e indeterminadas da contemporaneidade}

Mundializações ou globalizações? Qual seria a melhor nomenclatura? Os que defendem, como nós, a ideia da historicidade dos conceitos tenderia a chamar de mundializações os fenômenos sociais, econômicos e culturais vivenciados atualmente. Ocorre que, até para contestar as falsas ideias da unicidade e da inexorabilidade do processo, precisamos criticar uma literatura que já consagrou o termo globalização como definição do processo. Em outras palavras, o jogo hegemônico é tão denso que, até mesmo para contestar o conceito, a padronização proposital da linguagem nos obriga a usá-lo. Podemos perceber que até mesmo o termo a globalização faz parte do seu processo de convencimento, isto é, da construção da sua hegemonia. Mesmo assim, usando globalização como a nomenclatura corrente quer, temos que começar afirmando: não existe a globalização e, sim, globalizações hegemônicas e contrahegemônicas.

Boaventura de Souza Santos (2004) contrapõe e interliga as duas possibilidades históricas: a globalização contra-hegemônica, de que os movimentos e organizações congregadas no Fórum Social Mundial são um 
eloquente exemplo, é feita de uma enorme diversidade de ações de resistência contra a injustiça social em suas múltiplas dimensões. Contra a banalização e a instrumentalização da indignação moral procuram manter viva a ideia de que o capitalismo global (agora chamado de globalização neoliberal) é injusto, é hoje mais injusto do que há vinte anos e que, se nada fizermos, será ainda mais insuportavelmente injusto daqui a vinte anos. (...) O que será a globalização contra-hegemônica depende do que será a globalização hegemônica e viceversa (p. 1-2).

Neste sentido, torna-se importante destacar com Santos que

o objetivo da globalização alternativa é tornar o mundo cada vez menos confortável para o capitalismo. Este só pode ser declarado irreversível depois de esgotadas todas as alternativas, o que provavelmente nunca ocorrerá. Ou seja, o capitalismo global não é menos contingente e indeterminado do que as lutas contra ele. (Ibidem, p. 2).

Os desenvolvimentos interdependentes das globalizações antagônicas evidenciam um campo de luta que rechaça a ideia de fatalidade histórica. Por seu turno, os argumentos da contingência e da indeterminação alicerçam e tornam ainda mais incisivas as críticas sobre as falsas ideias do fim da história e da inexorabilidade da globalização como fenômeno único contra o qual não há nada a fazer. Ao contrário, para Santos (2002) o que é chamado de globalização é um "conjunto de arenas de lutas transfronteiriças" (p. 6). As globalizações "decima-para-baixo" (hegemônicas) e "de-baixo-para-cima" (contra hegemônicas) comportam quatro formas de globalização: o localismo globalizado e o globalismo localizado seriam parte da primeira e o cosmopolitismo e o patrimônio comum da humanidade, da segunda.

O localismo globalizado é o "processo pelo qual determinado fenômeno local é globalizado com sucesso". (Ibidem, p. 5). Cita como exemplos, entre outros, os casos das ações das multinacionais, a expansão mundial da língua inglesa e a globalização do fast food e da música popular norte-americanas. 0 globalismo localizado é mostrado pelo "impacto específico de práticas e imperativos transnacionais nas condições locais, as quais são, por essa via, desestruturadas e reestruturadas de modo a responder a esses imperativos 
transnacionais". (Ibidem, p. 5). Fazem parte dele os nossos conhecidos fenômenos como as zonas francas de comércio, "uso turístico de tesouros históricos, lugares ou cerimônias religiosas, artesanato e vida selvagem", "conversão da agricultura de subsistência em agricultura para exportação" (agrobusiness). Essas formas de globalizações hegemônicas teriam duas vias na divisão internacional da produção: "os países centrais especializam-se em localismos globalizados, enquanto aos países periféricos cabe tão-somente a escolha dos globalismos localizados". (Ibidem, p. 5).

No entanto, o cosmopolitismo e o patrimônio comum da humanidade não se caracterizam nem como globalismo localizado, nem como localismo globalizado. São formas antagônicas identificadas pelo autor como globalizações de-baixo-para-cima, ou seja, globalizações contra-hegemônicas. O cosmopolitismo constitui uma antítese das formas predominantes de hegemonia enquanto oportunidades de organizações transnacionais de Estados-nação, de regiões, de classes ou grupos sociais que explorariam as contradições do sistema mundial imposto, interagindo na defesa de seus interesses comuns. Incluem desde as redes feministas às ecológicas, das ONGs às organizações Sul-Sul, das organizações de trabalhadores aos Fóruns Mundiais, passando pelos movimentos literários, científicos e artísticos. 0 patrimônio comum da humanidade, por sua vez, inclui temas de sentido global como o desenvolvimento sustentável da Terra, a proteção da camada de ozônio, a preservação da floresta amazônica, dos oceanos e da Antártida (Santos, ibidem, p. 5-6). Fácil observar que, concomitante à expansão contrahegemônica, tem ocorrido fortes resistências que vão do combate às organizações como o Greenpeace à não assinatura pelos Estados Unidos do Tratado de Kyoto, passando inclusive pelas ações do Vaticano e do Governo Busch contra liberdade sexual, os avanços científicos no campo das célulastronco, entre outros. 


\section{Globalização da cultura e da educação \\ 2.1 Hegemonia e cultura educacional mundial comum}

Certamente não se admite que os processos hegemônicos de globalização estejam circunscritos aos campos econômicos e às suas relações mais próximas. As interferências desses processos nos campos da cultura e da educação têm sido objeto de vários estudos. Um dos mais significativos, a meu ver, é o trabalho desenvolvido por Roger Dale (2004), disseminado e traduzido em vários países, inclusive no Brasil ${ }^{2}$. Dale compara duas abordagens da relação globalização-educação: uma oriunda das teses de John Meyer (e da sua equipe da Universidade de Stanford, EUA) que considera a propagação de uma "cultura educacional mundial comum" (CEMC) e, outra, a sua própria abordagem, que denomina "agenda globalmente estruturada para a educação" (AGEE).

Segundo Dale, os que propõem a primeira abordagem "defendem que o desenvolvimento dos sistemas educativos nacionais e as categorias curriculares se explicam através de modelos universais de educação, de estado e de sociedade, mais do que através de fatores nacionais distintivos" (2004, p. 425). Por sua vez, Dale "baseia-se em trabalhos recentes sobre economia política internacional (...) que encaram a mudança de natureza da economia capitalista mundial como a força diretora da globalização e procuram estabelecer os seus efeitos, ainda que intensamente mediados pelo local, sobre os sistemas educativos". (Ibidem, p. 426).

A argumentação principal de Meyer e seus colaboradores é a de os estados estão modelados por uma ideologia dominante, cada vez teriam menos autonomia, e se submeteriam a normas e cultura homogeneizadoras. Segundo Dale, as pesquisas do grupo em foco constatam que a demonstração mais cabal dessa abordagem se encontra na área educacional "tanto na massiva e rápida expansão dos sistemas de educação nacionais como no inesperado isoformismo global das categorias curriculares em todo o mundo". (Ibidem, p. 427). E esse

\footnotetext{
${ }^{2}$ A tradução portuguesa publicada na Revista Educação, Sociedade \& Culturas (Porto, no16, 2001, p. 133-169) foi reproduzida na Revista Educação e Sociedade (Campinas, vol.25, nำ7, 2004, p. 423-460), considerada a principal revista brasileira na área educacional. Disponível em www.cedes.unicamp.br.
} 
isoformismo aconteceria sem levar em conta as distinções políticas, econômicas e culturais de cada nação. Para Meyer,

as estruturas formais da sociedade, desde a definição e propriedades do individual até a forma e o conteúdo de organizações como as escolas, as empresas, os movimentos sociais e os estados, derivam ou são ajustadas para se adequarem às regras muito gerais que possuem pelo mundo afora significado e poder".(MEYER, apud DALE, op.cit. p. 428).

Estes autores, que Dale denomina "institucionalistas mundiais", pensam as instituições como "instâncias culturais" fundadas na racionalidade, no progresso, no individualismo e na justiça. Atuariam "no sentido da racionalização do mundo social e da expansão das competências e direitos do indivíduo". Ainda segundo essa abordagem, as políticas nacionais de educação "são em essência pouco mais que interpretações de versões ou guiões que são informados por, e recebem a sua legitimação de, ideologias, valores e culturas de nível mundial". A maior demonstração dessa tese centra-se na "surpreendente homogeneidade das categorias curriculares" disseminadas em todo o mundo. (DALE, op. cit., p. 429).

De acordo com essa perspectiva, a educação de massas e os currículos da escola de massas estão estritamente ligados aos modelos emergentes de sociedade e de educação que se tornam relativamente padronizados em nível mundial. Estes modelos padronizados criaram efeitos culturais homogeneizantes que minam o impacto de fatores nacionais e locais ao determinarem a composição do currículo. Esta visão implica que as diferenças nacionais relativamente às prioridades curriculares - por exemplo, a prioridade dada à matemática ou às ciências - são relativamente pequenas e acabarão por se diluir ao longo do tempo. (KAMENS \& BENAVOT, apud Dale, op. cit. p. 432).

Em suma, a tese da cultural educacional mundial comum, ao vincular a globalização e os processos educacionais mediatizados pelos currículos, procura mostrar as ações das forças supranacionais, as causas determinantes da incorporação de um modelo ocidental (e pretensamente único) de mundo e as consequentes absorções educacionais e curriculares advindas dessa modelação. Como se pode imaginar desde logo, substanciam essa visão as 
interferências das agências financiadoras como o Banco Mundial, o BIRD, o BID, ou reguladoras como a OMC.

\subsection{Possibilidades contra- hegemônicas de uma agenda globalmente estruturada da educação}

Uma outra da visão da problemática globalização-educação é construída por Roger Dale (2004). Segundo o próprio autor, sua tese compartilha pontos importantes com a abordagem antes exposta, mas apresenta algumas diferenças fundamentais. Ambas argumentam sobre a influência das forças supranacionais sobre as políticas educacionais dos Estados-nação, reconhecendo que "os quadros interpretativos nacionais são moldados quer supranacionalmente, quer nacionalmente". As diferenças fundamentais residiriam nas compreensões da globalização e da educação e nas relações entre elas (p. 436).

Conforme Dale, a diferença fundamental entre as duas abordagens reside na compreensão da natureza do fenômeno global. Para a CEMC, trata-se de um reflexo da cultura ocidental, baseada cognitivamente em torno de um conjunto particular de valores que penetram em todas as regiões da vida moderna. Para a AGEE, a globalização é um conjunto de dispositivos político-econômicos para a organização da economia global, conduzido pela necessidade de manter o sistema capitalista, mais do que qualquer outro conjunto de valores. A adesão aos seus princípios é veiculada através da pressão econômica e da percepção do interesse nacional próprio. (Ibidem, p. 436)

$\mathrm{Na}$ abordagem defendida por Dale, a globalização seria "um conjunto de relações econômicas, políticas e culturais caracterizado por um hiperliberalismo, por uma governação sem governo e mercadorização e consumismo". (Ibidem, p. 436). Esse conjunto (no qual se incluem as políticas educacionais nacionais) e essas características seriam a base da expansão contínua e da legitimação do sistema capitalista.

Por outro lado, a agenda globalmente estruturada da educação preocupase em ampliar e detalhar a importância da política educacional e de suas implicações, mesmo a reconhecendo como variável dependente do processo. Dale quer saber: 
a quem é ensinado o quê, como, por quem e em que circunstâncias?; como, por quem e através de que estruturas, instituições e processos são definidas essas coisas, como é que são governadas, organizadas e geridas?; quais são as consequências sociais $e$ individuais destas estruturas $e$ processos? (Ibidem, p. 439).

Diferente da CEMC, na qual o caráter político da educação está estritamente subordinado ao econômico, na abordagem de Dale, além do econômico ser parte de um tripé (em conjunto com a política e a cultura), a educação não é seu mero reflexo ou somente sua consequência.

A segunda abordagem também se mostra distinta quanto às questões curriculares. Já havíamos entendido que Meyer e seus colaboradores defendem a ideia da padronização curricular a partir de uma matriz mundial homogeneizadora. Dale contesta. Além de criticar, por exemplo, a ausência de análise que contemplem as relações da educação com a desigualdade social, tanto em nível global como nacional, chama atenção para uma construção teórica que se limita à sala-de-aula, como se advogasse a neutralidade da prática curricular.

Para Dale, o padrão de governação educacional permanece em grande parte sob o controle do Estado, contudo novas e cada vez mais visíveis formas de desresponsabilização estão a prefigurar-se. A educação permanece um assunto intensamente político no nível nacional, e moldado por muito mais do que debates acerca do conteúdo desejável para a educação. As agendas nacionais para a educação são formadas mais no nível do regime do que no nível estrutural; as políticas educativas, o processo de determinar o conteúdo e o processo da educação são poderosamente moldados e limitados pelas políticas educativas, pelo processo de determinação das funções a serem desempenhadas, pela importância do consequente provimento dos seus recursos, pelo sistema educativo como parte de um quadro nacional regulador mais amplo. (Ibidem, p. 440-441)

E, arremata: De uma forma muito crítica, neste contexto, todos os quadros regulatórios nacionais são agora, em maior ou menor medida, moldados e determinados por forças supranacionais, assim como por forças político- 
econômica nacionais. E é por estas vias indiretas, através da influência sobre o Estado e sobre o modo de regulação, que a globalização tem seus mais óbvios e importantes efeitos sobre os sistemas educativos nacionais. (Ibidem, p. 441)

Neste caminho é importante enfatizar, ainda com Dale, que "as variações nacionais continuam fortes, que a cultura mundial está longe de ser homogênea e que a incorporação do modelo pode acontecer a um nível meramente ritual". (Ibidem, p. 443).

Entretanto, apesar das oposições patrocinadas pela abordagem da agenda globalmente estruturada da educação contra a teorização da cultura mundial educacional comum, o próprio Dale reconhece que uma tem propostas a oferecer à outra, ou seja, podem ser complementares. Esse autor defende a necessidade, contudo, da demonstração da existência de conteúdos programáticos comuns a todos os Estados-nação, isto é, de um currículo mundial comum. Isso implicaria o avanço de pesquisas empíricas neste sentido, mas, a meu ver, a principal diferenciação entre ambas está na crítica ao caráter cognitivista e politicamente neutro embutido nas defesas das teses da CEMC. Essas diferenças não são tópicas, ao contrário, revestem-se de grande importância. Tanto no entendimento das políticas nacionais de adesão aos modelos hegemônicos internacionais disseminados e/ou impostos, quanto nas tentativas de reversão desse quadro em busca de maior autonomia dos Estados-nação e das iniciativas contra-hegemônicas ao "localismo globalizado" e ao "globalismo localizado", antes apontadas por Boaventura de Sousa Santos.

\section{Contrapontos freireanos à globalização hegemônica na educação}

Depois de tentarmos caracterizar, ainda que brevemente, as globalizações, as convergências e divergências nas influências da globalização hegemônica na educação, nosso intuito neste segmento é pensar os possíveis contrapontos aos determinismos da globalização hegemônica por meio dos principais conceitos do pensamento político-pedagógico de Paulo Freire. Como poderíamos pensar/propor uma educação contribuinte de uma globalização contrahegemônica utilizando alguns dos principais conceitos da pedagogia crítica de 
Paulo Freire? Como a pedagogia freireana denunciaria a globalização hegemônica? Como a pedagogia freireana pensaria uma educação para a globalização contra-hegemônica, por meio da complexidade dos seus conceitos e práticas?

Parece-nos que o primeiro passo a considerar é a influência da pedagogia freireana no mundo. Sabemos que obra de Paulo Freire é traduzida, utilizada e debatida em vários idiomas e em muitos países. Em um sentido completamente diverso da globalização hegemônica do capitalismo, podemos dizer que Freire é um dos pensadores da educação e da pedagogia mais "globalizados". Os numerosos eventos, as publicações e as constantes referências à sua obra e ao seu legado prático-teórico demonstram a possibilidade concreta da sua pedagogia vir a ser um contraponto vigoroso à influência da globalização hegemônica na educação mundial.

Por que isso ocorre? A meu ver, porque suas categorias de análise, seus principais conceitos e a força da sua prática e das práticas educativas que utilizam seu legado em todo o mundo tem oferecido denúncias, respostas $e$ propostas convincentes aos principais problemas que as políticas educacionais enfrentam nos últimos quarenta anos, entre os quais destacam-se: bilhões de analfabetos absolutos, funcionais, digitais, políticos; precária escolarização das camadas sociais subalternas; privilégio da educação das elites; educação bancária; reprodução dos processos opressivos nas salas de aula; necessidade de reeducação dos educadores e de oferta de condições de trabalho adequadas e qualitativas; importância das ações dialógicas na educação; impossibilidade da educação neutra e a ênfase da politicidade da educação; necessidade da conquista da educação crítica pelas vias/estágios da consciência; aparato educacional voltado para os interesses, valores e necessidades das camadas oprimidas; combate aos determinismos práticos e teóricos; busca da consciência da realidade nacional; a educação e a cultura como exercícios da liberdade; os direitos dos oprimidos ao conhecimento; o trabalho como uma das matrizes do conhecimento político; a esperança e a ousadia que combatem o fatalismo e o medo; a construção da pedagogia da autonomia; as construções dos inéditos 
viáveis e da utopia da denúncia e do anúncio; enfim, a educação na história como possibilidade da mudança.

Talvez a mais grave das denúncias do fracasso das políticas educacionais lastreadas na globalização atualmente hegemônica seja a verificação de que o analfabetismo de bilhões de pessoas no mundo todo continua a nos desafiar e nos envergonhar. Tal fato já era desastroso havia quatro/cinco décadas, quanto mais hoje na chamada "sociedade do conhecimento" e da comunicação letrada. Os fracassos aos combates ao analfabetismo continuam, tanto em nível local como mundial. E o problema continua a ser tratado como denunciou Freire em um artigo dos anos 1970 (Revista Educação e Sociedade, no 1) denominado "Alfabetização de adultos: um quefazer neutro?", ou seja, os encaminhamentos não conseguem descer às raízes sócio-políticas do problema ficando, no máximo, em seu nível cognitivo, agora em discussões circulares sobre letramento etc. Certamente, que as discussões sobre cognição, sobre as metodologias e outras questões do gênero são importantes. No entanto, não há discussão mais urgente do que as necessidades e as determinações sociais e políticas a serem enfrentadas neste campo. No Brasil, o ensaio desse encaminhamento no início do atual governo quando, mais uma vez, a alfabetização parecia ser encarada como problema número um, foi relegado a um plano inferior. A velha questão do desenvolvimento nacional, levantada desde os anos 1930, permanece atual com agravantes: como desenvolver um país que tem mais de 100 milhões de analfabetos ${ }^{3}$ absolutos, funcionais, digitais, políticos etc.? E como não priorizar essa questão se ela tem reflexo direto no baixíssimo nível qualitativo da escolarização das camadas populares? Como decantar a importância da cidadania e da inserção no novo mundo do trabalho (competitivo e de competência) nos nossos Parâmetros Curriculares Nacionais, sem resolver essa problemática?

\footnotetext{
${ }^{3}$ Se somarmos os analfabetos absolutos e os funcionais (segundo a UNESCO aqueles que não completaram a $4^{\text {a }}$ série) já teremos, no Brasil, entre 60 e 70 milhões! Faltam os analfabetos digitais, políticos e outros. Ademais, o que dizer da constatação do SAEB/INEP de $74 \%$ dos alunos da $8^{a}$ série não dominam corretamente as quatro operações elementares da matemática? Ou a grande porcentagem que não consegue interpretar textos simples?
} 
Por outro lado, se a expansão quantitativa dos acessos aos vários níveis de escolaridade revelou-se uma positividade no período 1995-2002, como trabalhar com salas de aula repletas de dezenas alunos, sem investir no magistério e na docência? Se é verdade que o tempo médio de permanência na escola tem aumentado em todas camadas da população, o que dizer sobre a qualidade das nossas escolas? Mesmo sem analisar a capacidade de exclusão que a globalização hegemônica tem proporcionado - com seu crescente desemprego, com a brutal informalidade do mercado de trabalho e de outro lado, com as exigências de competência polivalente e tecnológica dos trabalhadores -, como fazer para que uma escolarização cada vez mais desqualificada seja parâmetro de inserção nesta mesma globalização? Em outras palavras, mesmo se aceitássemos (por mais absurdo que fosse) essa globalização, como faríamos para "adaptar e inserir" novos trabalhadores neste reinado mercadológico quando a qualidade da escolarização pública das camadas oprimidas desvanece? Como se pode notar com facilidade, se é notório que o âmbito correto da discussão passa pelo cognitivo, pelo "aprender a aprender, a fazer, a conviver e a ser" (Delors/UNESCO, 2000), nem de longe neste campo se detém. As grandes questões matriciais são eminentemente sociais e políticas, como sempre defendeu Freire. A ênfase dada por ele à denúncia da pseudoneutralidade educacional e a necessidade de compreender a inseparabilidade educação/política (SCOCUGLIA, 2003), bem como suas respectivas especificidades, não pode ser emudecida ou desprezada, ao contrário.

Em contrapartida, uma vez mais, a globalização hegemônica, de forma paradoxal para os seus próprios interesses do consumo e do lucro, parece mirar apenas a educação excludente. A disponibilidade dos meios da tecnologia da informação, por exemplo, ainda se dá em círculos mínimos. A Internet continua a ser acessada como instrumento de qualificação escolar e de trabalho por uma pequena parcela da sociedade. A velocidade de propagação do estilo consumista é intrinsecamente contraditória com os baixíssimos níveis de escolaridade já que, dentro da lógica perversa do sistema, os não escolarizados ou desqualificados na escolarização têm menos renda pessoal e familiar. A 
própria expansão do sistema privado de educação superior tem demonstrado, via de regra, a desqualificação do próprio sistema.

Podemos pensar que uma das evidências dessa desqualificação reside na continuidade da educação bancária, pois os depósitos de saber são incompatíveis com 0 crescimento intelectual e da consciência crítica, especialmente dos jovens e dos adultos. Em outras palavras, um sistema cognitivo que não serve nem para os propósitos de adaptação aos desígnios da globalização, quanto mais à reversão deste quadro. Deste prisma, a criatividade, a consciência crítica, a reflexão... passam ao largo, produzindo realmente um cidadão mudo, útil, solitário. Ademais, nossas salas de aula continuam a fabricar apatia, desinteresse e desigualdade e uma das suas reações tem sido a violência na escola, ou seja, a opressão combatida/respondida pela força bruta. Continua válida a observação da Pedagogia do Oprimido (Freire, 1984a): "o grande problema está em como poderão os oprimidos, que hospedam o opressor em si, participar da elaboração, como seres duplos, inautênticos, da pedagogia da sua libertação" (p. 32). E, sabemos todos que parte significativa da opressão se assenta, hoje, no binômio globalização econômica e neoliberalismo comercial.

Como se contrapor a tudo isso? Assim como a pedagogia freireana nos ajuda a denunciar estes fatos, ela pode contribuir para as respostas dessas problemáticas e para as propostas de formulação contra-hegemônica. Certamente, Freire não tem todas as respostas. Não podemos acreditar que um só pensador possua as respostas. Na literatura pertinente, cada vez mais, as teses freireanas são tecidas em conjunto com outras teses, outras propostas. Alguns pensadores agregaram as ideias de Freire com certas ideias de Gramsci. Outros o fizeram com Habermas. Outros ainda pensaram-nas com a contribuição de Amilcar Cabral, de Marx, de Freinet, ou mesmo de Morin. No nosso caso, até pela brevidade desta comunicação, não nos resta alternativas a não ser trabalhar as possíveis respostas e as propostas de Freire. Talvez possamos pensá-las com as ideias das globalizações contra hegemônicas (de-baixo-para-cima) do cosmopolitismo e do patrimônio comum da humanidade, indicados anteriormente por Boaventura de Souza Santos. 
Antes de mais nada, nossa busca de respostas e propostas inspiradas nos escritos de Freire deve estar alerta sobre a parte da cultura educacional que sofre completa redefinição e, por isso mesmo, o ataque mais incisivo por parte da globalização e do neoliberalismo: o currículo. Segundo Tomaz Tadeu da Silva (2001), "redefinir a educação como capitalista implica redefinir as próprias noções do que constitui conhecimento. O conhecimento deixa de ser um campo sujeito à interpretação e à controvérsia para ser simplesmente um campo de transmissão de habilidades e técnicas que sejam relevantes para 0 funcionamento do capital" (p. 8). Ainda segundo esse autor, "se a educação é o campo da batalha preferencial da luta social mais ampla em torno do significado, o currículo é, então, o ponto focal dessa luta". (Ibidem, p. 9).

Freire reconhece, desde os seus primeiros escritos das décadas de 1950 e 1960, o campo do currículo como área de disputa ferrenha de interesses políticos em torno dos processos educativos e, como núcleo central dessas disputas, as questões relativas ao conhecimento. Sua ênfase política recai principalmente sobre os direitos dos oprimidos ao conhecimento: (a) o direito de conhecerem melhor o que já conhecem da experiência feita; (b) o direito de conhecerem o que foi apropriado pelos opressores e lhes foi negado e (c) o direito de produzirem o seu próprio conhecimento (inerente aos seus próprios valores, interesses e necessidades sociais, culturais e políticas). Todos sabemos da sua forte defesa da educação problematizadora precisamente porque no seu contexto os oprimidos teriam vez e voz para discutirem seus problemas e as saídas organizadas para eles. Por isso mesmo é que a noção política da ação dialógica é decisiva. Para Freire, o diálogo deve ser uma arma dos oprimidos para se organizarem contra seus opressores. Podemos dizer que a educação e o currículo, ao contrário da unicidade e do determinismo que a hegemonia tenta impor, são arenas políticas nas quais os conhecimentos convergentes, divergentes e antagônicos combatem e, nesse combate, os oprimidos só podem mostrar sua fortaleza na ação coletiva dialógica de enfrentamento de quem os oprime.

Devemos ressaltar, também, a importância da reeducação dos educadores e o papel igualmente decisivo que jogam nessa disputa. Tem completa 
pertinência a crítica de Dale (2004) à teoria da disseminação avassaladora de uma cultura educacional mundial comum quando indagava: a quem é ensinado o quê, como, por quem e em que circunstâncias? Poderíamos, com Freire, completar: a favor de quê e de quem e, portanto, contra o quê e contra quem se educa? A favor de quê e de quem e, portanto, contra o quê e contra quem se constrói o currículo? Ao contrário do que propaga o determinismo hegemônico, o conhecimento e o currículo não são neutros, nunca. Representam, sempre, uma opção política, mesmo que esta seja francamente favorável à despolitização da sua discussão. E, por isso mesmo, continuam fundamentais as compreensões dos "estágios transitivos da consciência" mediados pela educação enquanto ação cultural da conquista do conhecimento crítico (FREIRE, 1984b).

Neste caminho, os debates sobre as globalizações hegemônicas e contrahegemônicas precisam ser tecidos em conjunto (complexus) e compostos pelos campos pedagógico, gnosiológico, cultural, político, dialógico, social, antropológico... além do campo econômico, como propõe Freire ao longo da sua obra. Sabemos que a priorização e a nuclearização em torno da economia já fazem parte da hegemonia, enquanto construção ideológica. Importante alertar com Reginaldo Moraes (2002) que "a narrativa neoliberal - produção de ideias, imagens, valores - descreve e pretende explicar os supostos despautérios do mundo social "regulado politicamente" (...). Não significa apenas nem principalmente definir respostas certas aos problemas, mas definir quais são os problemas certos e os termos em que devem ser equacionados. Seu alvo é modificar drasticamente os temas e os valores compartilhados, de modo que se enquadrem as eventuais alternativas no terreno pejorativo do impensável e se alterem em profundidade os espaços e os processos em que se fazem as escolhas sociais relevantes" (p.13).

Por isso, uma educação contribuinte para a globalização contrahegemônica precisa se nutrir, necessariamente, de uma pedagogia da esperança e da ousadia para combater a pedagogia do fatalismo e do medo. Precisa estar apta a garimpar e a escalar a autonomia para que seus 
protagonistas persigam a utopia, o inédito que é viável, enfim, a história como possibilidade do novo, da mudança. Para Freire (1993),

A importância do papel interferente da subjetividade na história coloca, de modo especial, a importância do papel da educação. A prática política que se funda na compreensão mecanicista da história, redutora do futuro a algo inexorável, castra as mulheres e os homens na sua capacidade de decidir, de optar, mas não tem força suficiente para mudar a natureza mesma da história. Cedo ou tarde, por isso mesmo, prevalece a compreensão da história como possibilidade, em que não há lugar para explicações mecanicistas dos fatos nem tampouco para projetos políticos de esquerda que não apostam na capacidade crítica das classes populares. Como processo de conhecimento, formação política, capacitação científica e técnica, a educação é prática indispensável aos seres humanos e deles específica na História como movimento, como luta. A história como possibilidade não prescinde da controvérsia, dos conflitos que, em si mesmos, já engendrariam a necessidade da educação, (1993, p.14).

Com efeito, como já escrevemos em outro trabalho, criticando o oportunismo de direita e, também, algumas raízes das teorias de esquerda que sustentam uma visão de mundo única e absoluta, Freire é incisivo ao rechaçar a pós-modernidade neoliberal e defender a pós-modernidade progressista e crítica. Para isso, aposta na possibilidade de concretização do que foi negado pela modernidade às camadas populares (aos oprimidos, aos subalternos, aos esfarrapados do mundo) e no rechaço do absolutismo da razão técnicaeconômica-instrumental que atrofiou as possibilidades concretas da hominização. Mas aposta, também, nas tendências pós-modernas que investem no respeito às diferenças, à diversidade, às questões de gênero e de etnia, dos direitos responsáveis por uma cidadania plena, planetária e multicultural para os que não tiveram (ou tiveram pouca) voz e vez e que continuam a se espalhar pelo mundo como sem-terra, sem-pão, sem-teto, sem-escola nenhuma ou semescola-de-qualidade, sem-emprego, sem-paz e, principalmente, sem-esperança, (SCOCUGLIA, 2004).

E, deste prisma, podemos encampar as reflexões de Peter McLaren (2001), segundo as quais "a pedagogia crítica serve, num sentido mais amplo, como 
uma hermenêutica política que orienta a articulação do significado vivido no interior das contingências da história, de acordo com um compromisso ético de justiça social. A pedagogia crítica tem se constituído como uma forma de navegar através das tecnologias de poder, criadas no interior dos terrenos contestados das culturas pós-modernas. A força da pedagogia crítica reside na sua capacidade para fortalecer o princípio da justiça social e para levar esse princípio ao domínio da esperança". Assim,

a pedagogia crítica deve avançar [...] como um meio de libertar os indivíduos das suas vidas socialmente isoladas, de forma que eles possam se tornar disponíveis para a sua imaginação coletiva. Entretanto, a política da imaginação também exige que imprimamos nossa vontade coletiva no funcionamento da história. Isto acontecerá quando, nos termos de Bordieu, nós formos capazes de dar à utopia uma possibilidade razoável de concretização. (2001, 97).

Nossos destaques às proposições de McLaren pretendem, além de ratificar a importância da pedagogia crítica - que tem em Paulo Freire um dos seus principais construtores e um dos seus principais referenciais prático-teóricos -, enfatizar a utilização do legado freireano (evidente nas palavras do autor citado) como um alicerce político-pedagógico das possibilidades das globalizações contra-hegemônicas. Afinal, a ação dialógica, a conquista da consciência crítica, a problematização, a pedagogia da autonomia, da ética e da justiça social podem vir a ser antíteses da educação que hoje ajuda a sustentar a globalização hegemônica e o neoliberalismo.

\section{Referências}

BORDIEU, P. e CHAMPAGNE, P. (1999). Os excluídos do interior. IN: CATANI, A. e NOGUEIRA (org.). Pierre Bordieu - Escritos de educação. Petrópolis: Vozes, p. 217-227.

DALE, R. (2004). Globalização e educação: demonstrando a existência de uma "cultura educacional mundial comum" ou localizando uma "agenda globalmente estruturada para a educação"? IN: Revista Educação e Sociedade. Campinas, vol. 25, no 87 , p. 423-460, maio/agosto.

DELORS, J. (2000). Educação - um tesouro a descobrir. São Paulo: Cortez/UNESCO. 
FREIRE, P. (1984a). Pedagogia do oprimido. Rio de Janeiro: Paz e Terra.

Paz e Terra.

(1984b). Ação cultural para a liberdade e outros escritos. Rio de Janeiro:

(1992). Pedagogia da esperança. São Paulo: Cortez.

(1993). Política e educação. São Paulo: Cortez.

(1996). Pedagogia da autonomia. São Paulo: Cortez.

MCLAREN, P. (2001). Traumas do capital: pedagogia, política e práxis no mercado global. IN: SILVA, L. H. da (org.). A escola cidadã no contexto da globalização.

Petrópolis: Vozes, p. 81-98.

MORAES, Reginaldo C. Reformas neoliberais e políticas públicas: hegemonia ideológica e redefinição das relações Estado-sociedade. Educ. Soc. [online]. set. 2002, vol.23, no.80 [citado 11 Maio 2005], p.13-24. Disponível na World Wide Web: $<$ http://www.scielo.br/scielo.php?script=sci arttext \&pid=S0101-

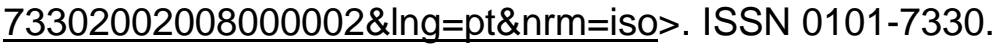

MORIN, E. (1998). O Método - As ideias. Porto Alegre: Sulina.

SANTOS, B. S. (2002). As tensões da modernidade IN: www.dhnet.org.br/direitos/militantes/boaventura/boaventura4.html.

SANTOS, B. S. (2004). Entrevista IN: www.ces.fe.uc.pt/BSS/documentos/JornalOGLOBNov2004.pdf.

SCOCUGLIA, A. C. (2003). A história das ideias de Paulo Freire e a atual crise de paradigmas. João Pessoa: Editora Universitária - UFPB (4ª edição).

SCOCUGLIA. A. C. (2004). Paulo Freire e a conscientização na transição pósmoderna. Trabalho apresentado no IV Congresso Internacional Fórum Paulo Freire. Porto/Portugal, setembro.

SCOCUGLIA, A. C. (2005). As reflexões curriculares de Paulo Freire. IN: Revista Lusófona de Educação. Lisboa, no 6, pp.81-92, dezembro.

SILVA, T.T. (2001). A escola cidadã no contexto da globalização. IN: SILVA, L. H. da (org.). A escola cidadã no contexto da globalização. Petrópolis: Vozes, pp.7-10. 